\title{
Research on the Plight of Landless Peasants in The Perspective of Social Capital
}

\author{
Chen $\mathrm{Yu}^{1}$ \\ ${ }^{I}$ School of Public Affairs and Administration, University of Electronic Science and Technology of China, Chengdu, Sichuan, \\ China \\ Corresponding author. Email:1062241709@qq.com
}

\begin{abstract}
As the urbanization process continues to accelerate, the landless peasant groups in the city have become larger and larger, which has become a difficult problem that cannot be ignored in urban governance. This article takes the Shunjiang community in Chengdu as an example, through field research and analysis of interview data to truly restore the urban life status of landless farmers. From the theoretical perspective of social capital, it is found that the marginalization of resettlement communities, the weakening of the functions of community organizations and the homogenization of social networks of land-lost farmers are the main dilemmas faced by land-lost farmers, due to the lack of government systems, insufficient cultivation of community organizations. The solidification of land-lost farmers requires the establishment of sustainable social capital cultivation mechanisms at the government, organizational, and individual levels to gradually realize the social integration of land-lost farmers.
\end{abstract}

Keywords: landless farmers, social capital, social integration, community settlement

\section{INTRODUCTION}

Land-lost farmers are a special group generated in the process of urbanization in China. Driven by national policies, the city-building movement was in full swing, and the expansion of the city occupied a lot of surrounding land, causing farmers to have to enter the city to become "upstairs" residents. However, the change in household registration status does not mean that this group is civicization. Due to the lack of government guarantees and the limitations of landless farmers 'own abilities, landless farmers have gradually become poor people in the city, which seriously affects the quality of urbanization and becomes a problem. Based on the field investigation of the case of Shunjiang Community, this article obtains first-hand interview materials and explores the causes of its integration into the dilemma from the perspective of social capital cultivation, with a view to improving the living conditions of landless farmers and promoting their urban integration.

\section{RESEARCH PERSPECTIVE: SOCIAL CAPITAL}

The vague concept of social capital was first proposed by Hannifin to illustrate the importance of social interaction to education and community. After the $1980 \mathrm{~s}$, the three founders of social capital theory appeared. Bourdieu made it clear that social capital is defined as "a collection of actual or potential resources", and believes that social capital is closely linked to social networks.[3]After that, American scholar Coleman applied the concept of social capital to the field of sociology for the first time. He defined social capital as "social structural resources owned by individuals", including social groups, social networks, and network ingestion.[4]Putnam introduced social capital into the field of political science. He believes that social capital is an organizational feature, such as trust,

reciprocity norms, and networks. Among them, social trust is the most critical factor in social capital.[5] Based on the research and contributions of these three people in this field, social capital has received extensive attention from scholars. Different scholars have interpreted social capital from different angles, which further enriches the theoretical connotation of social capital. In summary, this article mainly regards social capital as a resource closely connected with social networks, which can achieve the established goals by using social capital to obtain returns and returns; and uses this theoretical analysis to explain the current governance difficulties of Shunjiang community.

\section{FROM THE PERSPECTIVE OF SOCIAL CAPITAL, LANDLESS PEASANTS MERGE INTO THE PREDICAMENT}

\subsection{Isolated islands in cities: marginalized resettlement communities}

Driven by the government's coercive force, landless farmers are concentrated in the Shunjiang community in suburban counties of Chengdu, laying a hidden danger for the plight 
of the Shunjiang community. (1) Space isolation. The Shunjiang community was established earlier. It is located in a suburban county of Chengdu, far away from the city center, surrounded by farmland, and has relatively poor infrastructure and environment. It seems to have a natural barrier with other urban communities. (2) Insufficient resources. All kinds of land expropriation conflicts are essentially a matter of resources. Whether it is social security or compensation, they are the guarantee for the future life of the landless farmers and their sustainable survival in the city. At present, resettlement communities and land-lost farmers generally face the problem of insufficient resources, including post-relocation community support policies, community supporting public services, etc. These two problems lead to the lack of endogenous motivation for the resettlement community to integrate into the city, making it difficult to achieve sustainable development. In contrast to other newly built communities, the initially bright new community has slowly become an island on the edge of the city.

\subsection{Disintegrating social space: weakened community organizations}

Functionally, whether it is a formal or informal organization, its purpose is to better achieve community autonomy. In the eyes of residents, the neighborhood committee is the mouthpiece of the government and is "official". Because of their different positions, most residents "respect and respect" the neighborhood committee. From the perspective of the neighborhood committee, Mr. Zhang, a community worker, said: "Many things are not that we don't want to do, but because the street office has decentralized many administrative affairs to the community. It took a lot of time to complete these administrative affairs. Autonomous organizations have become a dual nature of administration and self-government, sandwiched between the government and residents, and neither side is pleased." From this, it can be seen that the Shunjiang community neighborhood committee is seriously administrative and has limited autonomy functions. In addition to the neighborhood committee, the Shunjiang community has also settled in some social organizations. From the cases and investigations, it can be seen that these social organizations are mainly concentrated in the field of entertainment. There is a lack of social organizations like rights protection that can promote the awakening of residents' public awareness. They have a single function and an audience. Narrow, the singing and dancing activities are unfriendly to middle-aged men like $\mathrm{Lao} \mathrm{Li}$; the number of interesting activities is small, indicating that the high-quality activities carried out by the community cannot meet the needs of current residents. In general, multiple subjects in the community are separated from each other, lacking trust and recognition among them, and unable to reach collective action on common interests. Because there is no harmonious interactive relationship and the social space within the community lacks structural support, it gradually disintegrates.

\subsection{Community circle of friends: homogeneous social network}

The residents of Shunjiang were farmers in nearby villages before the resettlement. The rural civilization has a profound influence. The neighborhood has built a "acquaintance society" based on blood and kinship. All people are in the same circle, and there is no inside. Too much difference in economic status. After the resettlement, the farmers were concentrated in the unitary urban community housing. The separation of space and area had a certain impact on the traditional "acquaintance society". The neighborhood relationship was not as good as before, but this concept of closeness and distance still affected Establishment of Shunjiang Resident Relations Network. Land-lost farmers generally have limited education, and tend to deal with people who are familiar with their own class in their daily life and work. It is difficult to reach strangers and higherlevel groups. The population quality is low, there is no reference to urban civilization, and there is insufficient motivation for individual development. In the long run, the circle of friends of residents is limited to the community level, forming a homogenous social network. In contrast, the socially integrated land-lost farmers in the Shunjiang community are well-educated, and in addition to the landlost farmers, there are teachers, classmates, colleagues, etc., and the circle of friends has expanded significantly after breaking the boundaries of resettlement communities. The social network structure is more diversified, which means that they can obtain more resources through this kind of relationship network to promote their own development, such as better job opportunities. Through the comparison of the two, the difference in economic status makes the residents of the Shunjiang community inevitably have a relative sense of deprivation and dissatisfaction with urban life and the community, but the limitations of knowledge and ideas make them unable to change the status quo, and ultimately show as Weak identification and weak participation in community governance.

\section{CAUSE ANALYSIS}

\subsection{Lack of system at the government level}

From a macro perspective of social capital, the biggest factor leading to the marginalization of resettlement communities is the lack of institutions. . The government occupies a dominant position, is the maker and executor of resettlement policies, and has absolute say in the resettlement process. Taking the Shunjiang community as an example, the local government's resettlement policy is mainly concentrated resettlement, giving one-time housing and monetary compensation, as if it is a set procedure. Tens of millions of resettlement communities have risen from the urban fringe. The urbanization rate has increased, but the resettlement community has not really been included in the urban development plan, and it has been transformed into an 
urban community. There is little institutional basis for the sustainable development of the resettlement community after its establishment. Compared with urban communities, resettlement communities are "congenitally inadequate" in terms of public resources and population quality. If the government should be a "hands-off" after resettlement, it will not plan well in the early stage, guide community development, and provide policy support for community construction. With the continuous expansion of the new city, there will be countless "shunjiang community" dilemmas that will become a major problem in urban governance.

\subsection{Insufficient cultivation of community organizations}

Community organization is an important part of the resettlement community. The key to the failure of the community organization in the Shunjiang community is the lack of organization cultivation. Formal organizations, such as neighborhood committees, should have been residents 'self-management, self-education, and self-service. Our grassroots self-governing organizations have evolved into a dual nature of administration and self-government in more than a decade. On the one hand, communities are the most basic unit of social governance In the end, many government policies will be implemented in the community, which requires the community neighborhood committee to spend a lot of energy and time to complete additional administrative affairs; on the other hand, the neighborhood committee is a representative of the community 's public opinion and should speak for the benefit of residents, but because Due to the over-administration of the organization and the problems of the quality of the staff, the neighborhood committees are lacking in services, gradually losing the trust of the residents and weakening the organization 's ability to mobilize. In informal organizations, the number of social organizations is small, the scale is small, the function is single, and the development is extremely uneven. Therefore, the types of activities carried out are limited, the audience is small, the competitiveness is not strong, it is difficult to form a scale effect in the community, and the overall recognition of the residents not tall. In summary, the development of both types of organizations in the community is restricted, and the accumulation of social capital at the meso level is difficult, and it is not enough to assume the important role of maintaining community stability and harmony.

\subsection{The solidification of the landless peasant class}

At the micro level, the focus is on the relationship network between people. In "Native China", the interpersonal relationship network of people in the village is called a difference order pattern, which separates relatives and distances based on blood and kinship, forming a stable social relationship structure. [2]After landless farmers enter the city, due to education restrictions, it is difficult to reach the high-income groups in the city. Under the general environment of centralized resettlement communities, they will tend to be the same as the living background and cultural background. Stratum exchanges, which are more closely connected with each other, forming a stable structure. Because the needs of daily interpersonal communication can be met within the group, land-lost farmers lose their willingness to contact strangers and form a homogenous social network. In the same group, land-lost farmers can hardly ingest enough resources to achieve personal crossover Due to the development of the stratum, when the individual 's micro social capital is seriously insufficient, land-lost farmers can only passively accept the status quo and lose the initiative to integrate into urban life and participate in community governance.

\section{COUNTERMEASURES \\ AND SUGGESTIONS TO GOVERN THE DILEMMA OF SHUNJIANG COMMUNITY}

\subsection{Improve the social support system of the resettlement community to achieve sustainable development}

Land requisition and resettlement is not a "one-shot sale", the ultimate goal is to realize the citizenization of land-lost farmers, the resettlement community into urban community. In order to achieve the sustainable development of the resettlement community, the government needs to strengthen the top-level design, provide help and support from the institutional level, and introduce third-party organizations to build a social support system for the resettlement community to achieve sustainable development. 1. Improve the flexibility of the resettlement policy. Government can try to convert the programmatic resettlement into dynamic resettlement, change the one-time large compensation to multiple small compensation, and adjust the compensation standard in a certain period according to the economic development situation, which can suppress the landless farmers when they receive large compensation The impulsive consumption can also achieve the sharing of economic development achievements of landless farmers. 2. Improve the resettlement community public service system. Most of the resettlement communities are located in remote areas of the city, and the level of public services such as education, medical care, and transportation are far away from the city center.

\subsection{Vigorously cultivate resettlement community organizations and reconstruct social space}

Community organizations are an important part of community governance. The development of community 
organizations affects the formation of a sense of trust, belonging, and identity within the community, and is related to the social capital accumulation of the entire community. On the one hand, the neighborhood committees must be deadministrative, which requires the decentralization of government, reducing direct interference with the neighborhood committees, liberating them from the complicated administrative affairs, and returning to the right track of serving residents; Comprehensive quality training to improve the overall service level of the community to gain the trust and praise of residents. On the other hand, we must actively introduce social organizations to provide residents with professional services. Through diverse social organizations such as entertainment, public welfare, and rights protection, we carry out diverse and rich community activities to mobilize the participation of most residents. Enthusiasm, in order to cultivate residents' autonomy and public spirit. Through vigorous cultivation of community organizations, it is conducive to improving community cohesion, restructuring social space, and establishing a stable and harmonious community community.

\subsection{Build a cross-class communication platform for landless farmers to promote social integration}

At the micro level, landless peasants belong to the immigrant population, and the available social capital has not yet been formed in the city. Due to their limited knowledge and ability, it is difficult to reach high-level social groups in the field of life and work. The homogenous social network structure is not conducive to landless peasants' bottom-up mobility, and social integration has become difficult. Therefore, under the circumstances that the landless peasants have limited individual strength, the government needs to use force to break down the barriers of communication between strata and build a cross-class communication and interaction platform for landless peasants. For example, the transformation from centralized resettlement to mixed resettlement makes landless farmers living in the same community, in the process of mutual communication, the value norms of the city will penetrate into their thoughts and behavior habits, and enhance their sense of identity to the city. The change of communication group is also conducive to the diversification of the social network of landless farmers. Through the continuous accumulation of social capital, more considerable resources can be obtained, which is conducive to the development of individual landless farmers and the promotion of social integration.

\section{CONCLUSION}

The problem of urban integration of landless farmers is a special product of China's rapid urbanization process. This huge social group has become the source of urban poverty. When the government considers low-cost and high- efficiency urbanization, it ignores the most basic survival and development needs of people. The spatial marginalization of landless farmers, the decline of community organizations and the homogenization of social networks essentially reflect the social capital of landless farmers. The fundamental reason for the lack of practical dilemma lies in the lack of government role in the survival and development of landless peasants. It does not provide effective and effective support measures for it. In the future, it must pay more attention to urban governance, improve the social support system, and vigorously cultivate Social organizations promote cross-sector exchanges among landless peasants, and ultimately achieve urban integration of this group.

\section{REFERENCES}

[1] Li Dongquan, Fang Hao. An Empirical Study on Community Governance Promoting Social Integration from the Perspective of Social Capital_-Taking Xiaojiahe Street in Chengdu as an Example [J]. Chongqing Social Sciences, 2019 (07): 65-74.

[2] Fei Xiaotong. Rural China [M]. Shanghai: Shanghai People's Publishing House, 2013: 4, 6, 24, 65 $80,59$.

[3] Bourdieu, Pierre, 1986, The forms of capital, in Richardson, John G. (ed.), Handbook of Theory and Research for the Sociology of Education, Westport, CT.: Greenwood Press.

[4] Coleman, J.S.1990: Foundations of Social Theory, Cambridge: Belknap.

[5] Robert D. Patnam, Wang Lie, Lai Hairong Translation: "Making Democracy Work", Jiangxi: Jiangxi People's Publishing House, 2001, p. 195. 